\title{
Dose-dependent effect of lysozyme upon Candida albicans biofilm
}

\author{
SARRA SEBAA $^{1,2}$, NICOLAS HIZETTE ${ }^{1}$, ZAHIA BOUCHERIT-OTMANI ${ }^{2}$ and PHILIPPE COURTOIS ${ }^{1,3}$ \\ ${ }^{1}$ Laboratory of Physiology and Pharmacology, Université Libre de Bruxelles, B-1070 Brussels, Belgium; \\ ${ }^{2}$ Laboratory of Antibiotics Antifungals: Physico-Chemistry, Synthesis and Biological Activity, University of \\ Aboubekr Belkaïd-Tlemcen, Tlemcen 13000, Algeria; ${ }^{3}$ Haute Ecole F. Ferrer, B-1070 Brussels, Belgium
}

Received August 9, 2016; Accepted December 7, 2016

DOI: $10.3892 / \mathrm{mmr} .2017 .6148$

\begin{abstract}
The present study investigated the in vitro effect of lysozyme $(0-1,000 \mu \mathrm{g} / \mathrm{ml})$ on Candida albicans (C. albicans) biofilm development. Investigations were conducted on $C$. albicans ATCC 10231 and on 10 clinical isolates from dentures. Strains were cultured aerobically at $37^{\circ} \mathrm{C}$ in Sabouraud broth. Yeast growth was evaluated by turbidimetry. Biofilm biomass was quantified on a polystyrene support by crystal violet staining and on acrylic surfaces by counts of colony forming units. Lysozyme affected biofilm formation to a greater extent than it affected growth. For the ATCC 10231 reference strain, lysozyme acted as a biofilm promotor on polystyrene at the highest concentration tested $(1,000 \mu \mathrm{g} / \mathrm{ml}$, non-physiological). When the reference strain was investigated on acrylic resin support, lysozyme acted as a significant biofilm promotor on rough resin, but less on smooth resin. The attached biomass in the presence of physiological concentrations of lysozyme (10-30 $\mu \mathrm{g} / \mathrm{ml}$ ) was significantly decreased compared with the hypothetical value of $100 \%$ using a one-sample $t$-test, but a comparison between the different lysozyme conditions using analysis of variance and post hoc tests did not reveal significant differences. In 10 wild strains, different patterns of biofilm formation on polystyrene were observed in the presence of lysozyme. Some strains, characterized by large amounts of biofilm formation in the presence of $1,000 \mu \mathrm{g} / \mathrm{ml}$ lysozyme, were poor biofilm producers at low concentrations of lysozyme. In contrast, some strains that were poor biofilm producers with a high lysozyme concentration were more inhibited by low concentrations of lysozyme. The present study emphasizes the need to develop strategies for biofilm control based on in vitro experiments, and to implement these in clinical trials prior to approval of hygiene products enriched with exocrine proteins, such as lysozyme. Further studies will extend these investigations to other Candida species, and to fungi and bacteria present in oral biofilms.
\end{abstract}

Correspondence to: Dr Philippe Courtois, Laboratory of Physiology and Pharmacology, Université Libre de Bruxelles, 808 Route de Lennik, B-1070 Brussels, Belgium

E-mail: philippe.courtois@ulb.ac.be

Key words: C. albicans, biofilm, dentures, lysozyme, yeast

\section{Introduction}

Candida albicans (C. albicans), a commensal yeast in the oral cavity, can incorporate into biofilms that form on denture surfaces $(1,2)$, leading in some cases to mucosal infections referred to as denture stomatitis (3-5).

Lysozyme, an antimicrobial protein present in exocrine secretions (6) and in phagocytes (7), contributes along with other innate non-immune factors in saliva to the control of the oral microflora, thereby preserving health of the mucosa and the dental surfaces $(3,8,9)$. The antimicrobial action of lysozyme is mediated through its muramidase activity (10) which catalyzes the hydrolysis of $\mathrm{N}$-acetyl-muramic/N-acetyl-glucosamine bonds in peptidoglycans composing the cell wall in Gram-positive bacteria (11). Lysozyme in the oral cavity comes from the salivary glands, particularly the submandibular and sublingual glands $(12,13)$, and from neutrophils arriving in the oral environment through gingival fluid in the healthy mouth (14) or crevicular fluid in periodontitis $(15,16)$. Physiological lysozyme concentrations in saliva range from 1 to $57 \mu \mathrm{g} / \mathrm{ml}$ (17).

Previous studies have investigated the effect of lysozyme on $C$. albicans blastoconidia $(3,18)$, but the mechanisms of action remain unclear. The three modes of action of lysozyme on C. albicans are its muramidase-like activity $(19,20)$, its cationic nature capable of destabilizing the cell membrane (21), and its agglutination property (22). Although no peptidoglycan substrate for muramidase activity exists in C. albicans, lysozyme-induced wall-like material deposits between its chitin wall and its cell membrane have been observed by electron microscopy (19). Synergistic action of lysozyme with other salivary proteins has been suggested by several authors as a mechanism of action towards C.albicans, and some oral care products already combine lysozyme with lactoferrin and lactoperoxidase (23-25). Indeed, in vitro investigations have shown that $C$. albicans susceptibility to lysozyme increases when combined with peroxidase $(26,27)$ but not with lactoferrin (28), while hyaluronic acid inhibits the lysozyme effect on C. albicans (27,29). Lysozyme also enhances the activity of antimycotic drugs such as polyenes and azoles (30-33).

A lower excretion of antimicrobial proteins in saliva has been demonstrated to promote $C$. albicans growth in the oral cavity (34). The in vitro effect of lysozyme on C. albicans biofilms remains controversial: certain studies demonstrated no beneficial effect of artificial saliva-containing lysozyme and 
other salivary proteins on yeast adhesion to acrylic resin (35), while others demonstrated a preventive role for lysozyme with respect to C. albicans biofilm formation on dentures (33). To the best of our knowledge, no studies have explored the link between $C$. albicans biofilm formation and lysozyme agglutination properties, previously described at $1 \mathrm{mg} / \mathrm{ml}$ concentration (22). The aim of the present in vitro study was to investigate whether lysozyme modulates $C$. albicans biofilm production when present in physiological concentrations, by triggering distinct mechanisms, namely inhibition and aggregation.

\section{Materials and methods}

Microorganisms. Yeasts were grown aerobically at $37^{\circ} \mathrm{C}$ on Sabouraud agar with $0.4 \mathrm{~g} / 1$ chloramphenicol and $0.04 \mathrm{~g} / \mathrm{l}$ gentamycin (BD Diagnostics, Franklin Lakes, NJ, USA). All in vitro investigations were conducted on a third subculture of C.albicans ATCC 10231 (Oxoid; Thermo Fisher Scientific, Inc., Waltham, MA, USA) suspended in Sabouraud broth (cat. no. CM147; Oxoid ${ }^{\mathrm{TM}}$; Thermo Fisher Scientific, Inc.) or in distilled water. The suspension was adjusted to $1-20 \times 10^{6}$ blastoconidia per $\mathrm{ml}$ by dilution, following a blastoconidia count using a Thoma cell counting chamber (Marienfeld ${ }^{\mathrm{TM}}$, Lauda-Königshofen, Germany). Wild strains were isolated by swabbing from dentures and identified on the basis of their colony aspect on CHROMagar ${ }^{\mathrm{TM}}$ medium (BD Diagnostics), by chlamydoconidia formation on $\mathrm{BT}^{\mathrm{TM}}$ Rice Extract agar (BD Diagnostics) and by the API yeast identification system (bioMérieux, Marcy-l'Etoile, France).

Lysozyme. Lysozyme from chicken egg white was purchased from Sigma-Aldrich; Merck Millipore (Darmstadt, Germany) with a molecular mass of $14,307 \mathrm{kDa}$ and an isoelectric point of 11.35. Final concentrations in reaction media ranged from $3-1,000 \mu \mathrm{g} / \mathrm{ml}(0.2-70 \mu \mathrm{M})$.

Biofilm production. Yeast biofilms were prepared in polystyrene flat bottom 96-well plates (Greiner Bio-One, Frickenhausen, Germany) by seeding $2 \times 10^{6}$ yeast cells per well and incubating at $37^{\circ} \mathrm{C}$ for $24 \mathrm{~h}$ in liquid Sabouraud medium with increasing concentrations of lysozyme $(3-1,000 \mu \mathrm{g} / \mathrm{ml}$ in $250 \mu \mathrm{l}$ total volume per well). Yeast growth was evaluated by spectrophotometry at $600 \mathrm{~nm}$ on a Packard SpectraCount microplate reader (Thermo Fisher Scientific, Inc.) and the attached biomass was quantified by crystal violet staining following washing in $0.9 \% \mathrm{NaCl}$ and fixation in $100 \%$ methanol. For a set of 4 experiments, $125 \mu \mathrm{l}$ from each well was transferred directly after incubation into a new 96-well plate, washed in $0.9 \% \mathrm{NaCl}$ and evaluated by spectrophotometry at $600 \mathrm{~nm}$. Data were compared with untreated control. Negative controls, namely wells without any yeast seeded, attested to the absence of accidental cross-well contamination during handling. Controls with $25 \mu \mathrm{g} / \mathrm{ml}$ amphotericin $\mathrm{B}\left(\mathrm{Gibco}^{\mathrm{TM}}\right.$, Thermo Fisher Scientific, Inc.) assessed the efficiency of a reference antifungal drug.

Crystal violet staining. Biofilm biomass was evaluated by crystal violet staining [procedure adapted from (36)]. Following aspiration of the well contents and three washes with sterile $0.9 \% \mathrm{NaCl}(250 \mu \mathrm{l}$ per well), the attached biomass was fixed with $250 \mu 1$ 100\% methanol (Sigma-Aldrich; Merck Millipore) for $15 \mathrm{~min}$. Biofilms were then stained by the addition of 2\% Hucker crystal violet solution for $5 \mathrm{~min}$ and rinsed under running tap water and dried. Crystal violet dye in the biofilm was solubilized in $2 \mathrm{M}$ acetic acid (250 $\mu \mathrm{l}$ per well) for $30 \mathrm{~min}$. The absorbance of each well was measured at $600 \mathrm{~nm}$ on a Packard SpectraCount microplate reader (Thermo Fisher Scientific, Inc.). Absorbance readings $>2$ were determined by diluting samples 10 -fold in $2 \mathrm{M}$ acetic acid, then measuring the absorbance and multiplying by 10 .

C. albicans adhesion onto resin pieces. Acrylic resin (Palapress, Heraeus Kulzer, Hanau, Germany) pieces $(2.56 \times 18.30 \pm 0.10 \times 4.60 \pm 0.10 \mathrm{~mm})$ were produced by a conventional muffle formatting method similar to that used for removable denture manufacturing; one side was polished (smooth surface) and the other was not (rough surface). Acrylic pieces were stored at $4^{\circ} \mathrm{C}$ in $0.1 \%(\mathrm{w} / \mathrm{v})$ sodium azide. For biofilm production, each resin piece was transferred to a Falcon polypropylene $15 \mathrm{ml}$ conical bottom tube (BD Biosciences), washed three times with $4 \mathrm{ml}$ sterile distilled water for $5 \mathrm{~min}$ at room temperature with gentle stirring at $3 \mathrm{rpm}$ (SB3 Stuart Rotator Holder, Bibby Scientific, Stone, Staffordshire, UK), rinsed in Sabouraud liquid medium for $5 \mathrm{~min}$, and finally immersed in $4 \mathrm{ml}$ fresh Sabouraud medium containing a C. albicans ATCC 10231 suspension $\left(10^{5}\right.$ blastoconidia per $\mathrm{ml}$ ) and lysozyme (10 or $1,000 \mu \mathrm{g} / \mathrm{ml})$. Controls were performed without lysozyme. Following incubation for $4 \mathrm{~h}$ at $37^{\circ} \mathrm{C}$ with continuous rotary agitation at $3 \mathrm{rpm}$ to prevent cells from sedimentation, the liquid phase was aspirated and each resin piece was transferred into a new clean Falcon tube by sliding. Resin pieces were then washed three times in sterile $0.9 \% \mathrm{NaCl}$. Swabs from each surface (rough or smooth) were serially seeded onto four different Petri dishes containing Sabouraud solid medium with $0.4 \mathrm{~g} / 1$ chloramphenicol and $0.04 \mathrm{~g} / 1$ gentamycin, in order to recover the adherent yeast cells. All plates processed from resin pieces were incubated for $48 \mathrm{~h}$ at $37^{\circ} \mathrm{C}$ before a colony forming unit (CFU) count was performed.

Fluorescence staining assay. Fresh solutions of fluorescein diacetate (FDA; $5 \mathrm{mg} / \mathrm{ml}$ in acetone) and ethidium bromide (EB; $5 \mathrm{mg} / \mathrm{ml}$ in PBS) were separately diluted 100 -fold in PBS and then mixed at a 1:1 ratio. Fluorescent reagent and C. albicans biofilm suspended in PBS were mixed at a 1:1 ratio and incubated for $15 \mathrm{~min}$ at $37^{\circ} \mathrm{C}$ prior to microscopic examination (Leica DM2000; Leica Microsystems, GmbH, Wetzlar, Germany). Green-fluorescence was considered as a marker of living cells and orange as dead cells. As a control, the assay was conducted with $C$. albicans ATCC 10231 blastoconidia before and after a $30 \mathrm{~min}$ incubation at $80^{\circ} \mathrm{C}$, which resulted in $100 \%$ live and dead cells, respectively.

Statistical analysis. Data were analyzed by the Kolmogorov-Smirnov test, one-sample t-test, unpaired Student's t-test, analysis of variance (ANOVA) with Dunnett's post hoc test, two-way ANOVA, the Mann-Whitney test, the Wilcoxon signed rank test, and the Kruskal-Wallis test with Dunn's multiple comparison post hoc test using GraphPad 
A

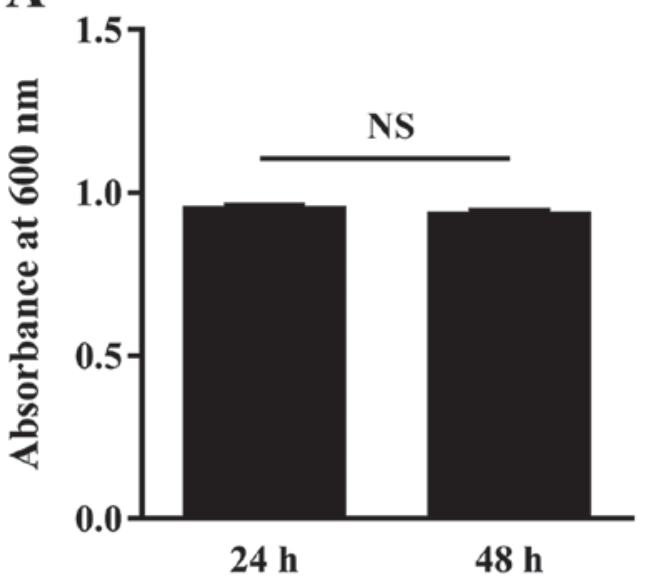

B

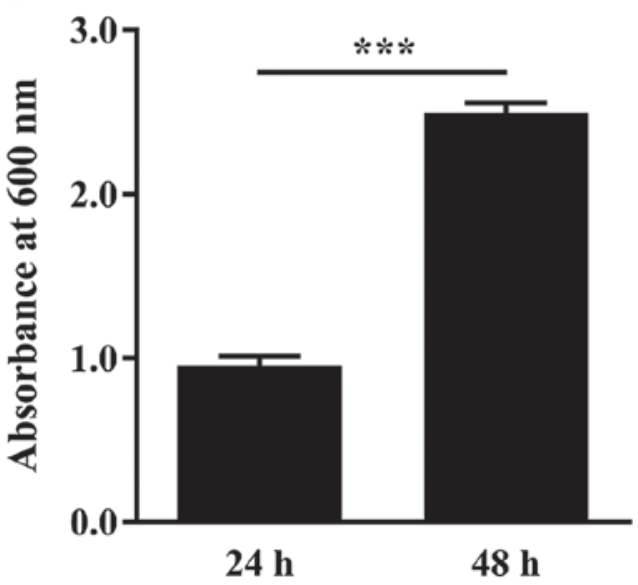

Figure 1. Effect of cultivation time ( 24 vs. 48 h at $\left.37^{\circ} \mathrm{C}\right)$ on Candida albicans ATCC 10231 evaluated by (A) turbidimetry and (B) biofilm production (attached biomass) which was evaluated by crystal violet staining. Data are expressed as the mean \pm standard error $(n=16$ in one independent experiment). NS, not significant and ${ }^{* * *} \mathrm{P}<0.001$, with comparisons indicated by lines.

Prism version 7.01 (GraphPad Software, Inc., La Jolla, CA, USA). Data are expressed as the mean \pm standard error of the mean, unless indicated otherwise. $\mathrm{P}<0.05$ was considered to indicate a statistically significant difference.

\section{Results}

C. albicans ATCC 10231 biofilm formation on polystyrene. In a preliminary experiment, $C$. albicans ATCC 10231 was cultured at $37^{\circ} \mathrm{C}$ for 24 and $48 \mathrm{~h}$, then Sabouraud broth turbidity and attached biomass were measured by absorbance at $600 \mathrm{~nm}$ and crystal violet staining, respectively. Turbidity absorbance measurements were $0.958 \pm 0.003$ following incubation for $24 \mathrm{~h}$ and remained similar following $48 \mathrm{~h}$ incubation $(0.941 \pm 0.005$; Fig. 1A). However, measurements of the attached biomass were significantly increased, by 2.6 -fold, at $48 \mathrm{~h}$ compared with $24 \mathrm{~h}(\mathrm{P}<0.0001$; Fig. 1B).

The effect of various concentrations of lysozyme $(0-1,000 \mu \mathrm{g} / \mathrm{ml})$ on $C$. albicans ATCC 10231 growth in Sabouraud liquid medium was measured next (Fig. 2). Lysozyme concentrations $\geq 300 \mu \mathrm{g} / \mathrm{ml}$ significantly reduced
A

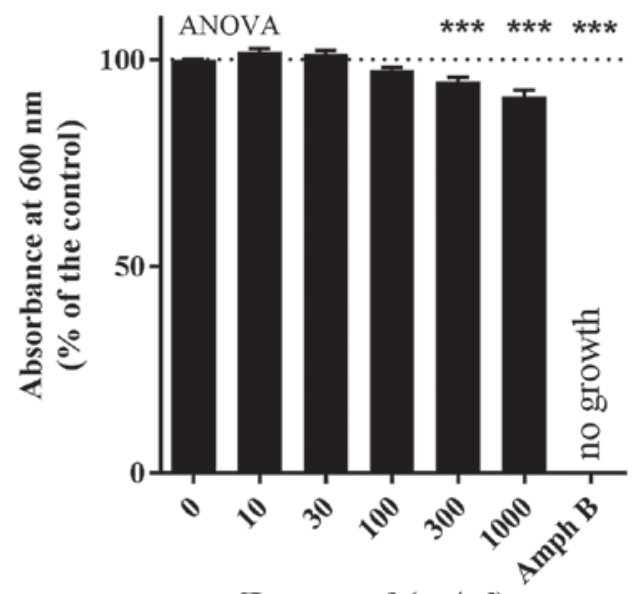

[Lysozyme] $(\mu \mathrm{g} / \mathrm{ml})$

B

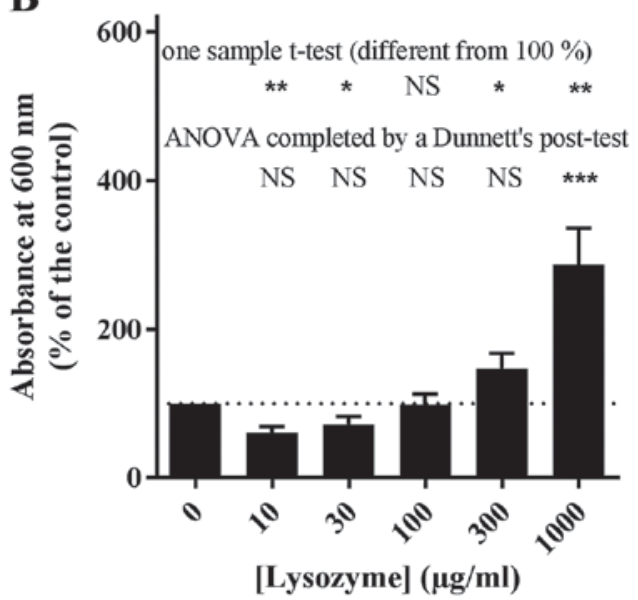

Figure 2. Effect of lysozyme on Candida albicans ATCC 10231 growth. Yeast cells were grown at $37^{\circ} \mathrm{C}$ for $24 \mathrm{~h}$ in the presence of $0,10,30,100$, 300 or $1,000 \mu \mathrm{g} / \mathrm{ml}$ lysozyme. Amph B treatment $(25 \mu \mathrm{g} / \mathrm{ml})$ was used as a negative growth control. (A) Growth was measured by turbidimetry. (B) In vitro biofilm formation was evaluated by crystal violet staining. Data are expressed as the mean \pm standard error $(n=7-10$ independent experiments, 8 technical replicates each). NS, not significant, ${ }^{*} \mathrm{P}<0.05,{ }^{* *} \mathrm{P}<0.01,{ }^{* * * *} \mathrm{P}<0.001$. Dunnett's post-test compares each column with control without lysozyme. Amph B, amphotericin B.

C. albicans growth compared with the untreated control $(\mathrm{P}<0.0001)$; a reduction of $5.3 \pm 0.9$ and $9.0 \pm 1.6 \%$ relative to the untreated control was measured at 300 and $1,000 \mu \mathrm{g} / \mathrm{ml}$ of lysozyme, respectively (Fig. 2A). Lysozyme concentrations $<100 \mu \mathrm{g} / \mathrm{ml}$ had no effect on $C$. albicans growth compared with the untreated control (Fig. 2A). Amphotericin B (25 $\mu \mathrm{g} / \mathrm{ml})$ completely prevented growth and, consequently, the formation of biofilms (Fig. 2A). Fig. 2B illustrates the effect of lysozyme treatment on $C$. albicans ATCC 10231 biofilm formation in 96-well plates. Lysozyme produced a significant biphasic effect on biofilm formation (Fig. 2B), despite its relatively limited effect on yeast growth (Fig. 2A). Lysozyme acted as a biofilm promotor at the highest concentration tested $(1,000 \mu \mathrm{g} / \mathrm{ml})$, but as a biofilm limiting factor at the lowest concentrations $(10-30 \mu \mathrm{g} / \mathrm{ml})$. At $1,000 \mu \mathrm{g} / \mathrm{ml}$, the attached biomass averaged $286.8 \pm 49.0 \%$ relative to the control, however, at $10 \mu \mathrm{g} / \mathrm{ml}$ lysozyme, the attached biomass was $60.9 \pm 8.3 \%$ relative to the control (Fig. 2B). An ANOVA analysis with Dunnett's multiple comparison test and a 
Table I. Effect of lysozyme on Candida albicans ATCC 10231 attached biomass.

A, All reagents added at time zero

\begin{tabular}{lccccccc}
\hline Lysozyme $(\mu \mathrm{g} / \mathrm{ml})$ & 0 & 3 & 10 & 30 & 100 & 300 & 1,000 \\
\hline$\%$ (mean \pm SEM) & $100.0 \pm 2.5$ & $81.1 \pm 4.1$ & $98.4 \pm 4.1$ & $124.6 \pm 10.3$ & $482.4 \pm 25.4$ & $923.6 \pm 33.8$ & $958.2 \pm 21.1$ \\
$\mathrm{~N}$ & 16 & 8 & 8 & 8 & 8 & 8 & 8 \\
P-value (vs. $0 \mu \mathrm{g} / \mathrm{ml})$ & - & 0.8786 & 0.9999 & 0.7064 & $<0.0001$ & $<0.0001$ & $<0.0001$ \\
\hline
\end{tabular}

$\mathrm{B}$, Culture medium renewal and lysozyme addition after $2 \mathrm{~h}$ pre-incubation

\begin{tabular}{lccccccc}
\hline Lysozyme $(\mu \mathrm{g} / \mathrm{ml})$ & 0 & 3 & 10 & 30 & 100 & 300 & 1,000 \\
\hline$\%$ (mean $\pm \mathrm{SEM})$ & $100.0 \pm 6.0$ & $60.1 \pm 1.6$ & $81.8 \pm 4.1$ & $73.5 \pm 11.1$ & $106.8 \pm 10.0$ & $118.0 \pm 6.8$ & $141.3 \pm 10.7$ \\
$\mathrm{~N}$ & 16 & 8 & 8 & 8 & 8 & 8 & 8 \\
$\mathrm{P}$-value (vs. $0 \mu \mathrm{g} / \mathrm{ml})$ & - & 0.0013 & 0.2950 & 0.0533 & 0.9643 & 0.3081 & 0.0008 \\
\hline
\end{tabular}

Attached biomass of $C$. albicans ATCC 10231 was evaluated following a $48 \mathrm{~h}$ incubation at $37^{\circ} \mathrm{C}$ in 96 -well plates with $0,3,10,30,100$ or $1,000 \mu \mathrm{g} / \mathrm{ml}$ lysozyme. Evaluation was performed by two different experimental designs: (A) Lysozyme addition at time zero, and (B) culture medium renewal with the addition of lysozyme following a $2 \mathrm{~h}$ preincubation of $C$. albicans cells. Data are expressed as the mean $\%$ of the control ( \pm standard error). Statistical analysis was performed by analysis of variance, followed by Dunnett's multiple comparisons post hoc test.

A

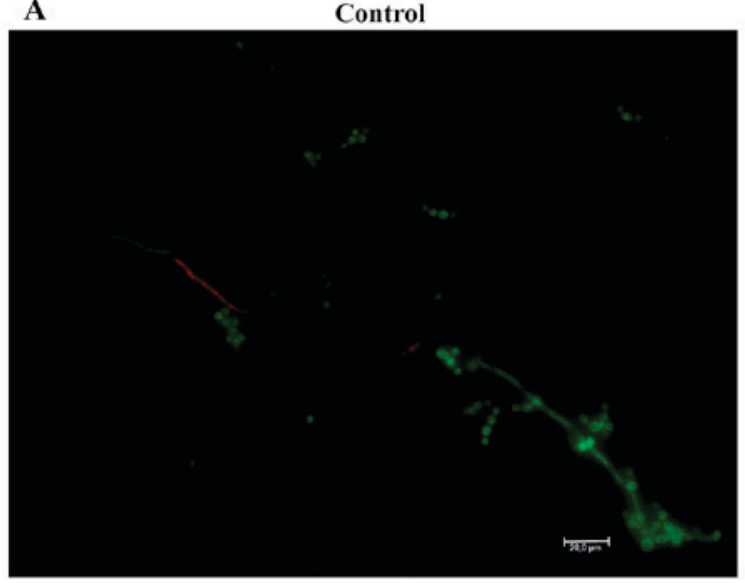

B

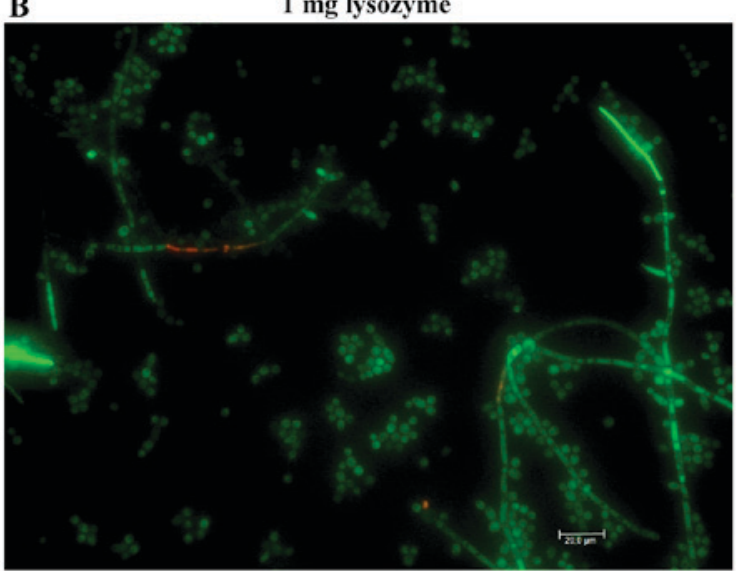

Figure 3. Fluorescence fluorescein diacetate/ethidium bromide staining of Candida albicans ATCC 10231 biofilms harvested from the bottom of wells following incubation (A) without lysozyme or (B) with $1,000 \mu \mathrm{g} / \mathrm{ml}$ lysozyme. Green indicates living cells and orange indicates dead cells.

one-sample t-test confirmed the biofilm promoting effect of $1,000 \mu \mathrm{g} / \mathrm{ml}$ lysozyme $(\mathrm{P}<0.001$ and $\mathrm{P}=0.004$, respectively; Fig. 2B). The attached biomass in the presence of $10-30 \mu \mathrm{g} / \mathrm{ml}$ lysozyme was significantly different from the control by one-sample $t$-test $(\mathrm{P}=0.0059$ and $\mathrm{P}=0.0371$, respectively; Fig. 2B), but analysis by ANOVA did not reveal significant differences (Fig. 2B).

Fig. 3 illustrates the characteristics of C. albicans biofilms harvested from the bottom of the wells following incubation with $1,000 \mu \mathrm{g} / \mathrm{ml}$ lysozyme. Microscopic examination revealed that the majority ( $>95 \%$ ) of $C$. albicans cells (blastoconidia with some hyphal structures) were live as in the control without lysozyme (Fig. 3). C. albicans ATCC 10231 attached biomass was evaluated by 2 different experimental designs following $48 \mathrm{~h}$ incubation at $37^{\circ} \mathrm{C}$ in 96 -well plates: Direct addition of lysozyme at time zero (Table IA), as previously performed for the $24 \mathrm{~h}$ observations displayed in Figs. 2 and 3; and culture medium renewal with the addition of lysozyme following a $2 \mathrm{~h}$ preincubation of $C$. albicans cells to allow time for adherence (Table IB). Independent of the incubation time ( 24 vs. $48 \mathrm{~h}$ ), addition of lysozyme to planktonic cells resulted in an increase in attached biomass compared with the untreated control, with the increase being higher after $48 \mathrm{~h}$ (Table I). Treatment with 1,000 $\mu \mathrm{g} / \mathrm{ml}$ lysozyme resulted in a 9.6-fold increase in attached biomass compared with control $(\mathrm{P}<0.0001$; Table IA). When biofilm production was examined following $C$. albicans pre-adherence, a less significant 1.4-fold increase in attached biomass was observed in the presence of 1,000 $\mu \mathrm{g} / \mathrm{ml}$ lysozyme compared with control ( $\mathrm{P}=0.0008$; Table IB), while lysozyme at physiological concentrations $(<30 \mu \mathrm{g} / \mathrm{ml})$ always reduced biomass (Table I). 
Biofilm formation on polystyrene by $C$. albicans wild strains. The effect of lysozyme on 10 wild $C$. albicans strains isolated from different dentures was then examined by turbidimetric growth and biofilm evaluation. No significant effect of lysozyme $(0-1,000 \mu \mathrm{g} / \mathrm{ml})$ on the growth of wild strains in Sabouraud liquid medium was observed, apart from a slight but non-significant decrease at $1,000 \mu \mathrm{l} / \mathrm{ml}$, which was the highest concentration tested (Fig. 4A). Amphotericin B $(25 \mu \mathrm{g} / \mathrm{ml})$ completely prevented the growth of yeast and biofilm formation (data not shown), similar to the results for the reference strain (Fig. 2A). The effect of lysozyme $(0-1,000 \mu \mathrm{g} / \mathrm{ml})$ on the ability of the wild strains to form biofilms on 96-well plates was subsequently assessed (Fig. 2B). The results demonstrated variable patterns of biofilm formation (Fig. 4B). Some strains demonstrated large quantities of biofilm production in the presence of a high lysozyme concentration $(1,000 \mu \mathrm{g} / \mathrm{ml})$ but poor biofilm production at low concentrations (Fig. 4B). Other strains that exhibited poor biofilm production with a high lysozyme concentration were further inhibited by weak concentrations (3-30 $\mu \mathrm{g} / \mathrm{ml}$; Fig. 4B). Only one wild strain out of ten was inhibited by lysozyme in a dose-dependent manner (Fig. 4B). Overall, in the 10 clinical strains isolated from dentures, the attached biomass following incubation with $1,000 \mu \mathrm{g} / \mathrm{ml}$ lysozyme ranged from 36.1 to $3825.0 \%$ compared with untreated controls (mean, 548.4\%; median, 191.4\%; non-Gaussian distribution; Fig. 4B). However, at $3 \mu \mathrm{g} / \mathrm{ml}$ lysozyme, the attached biomass ranged from 26.3 to $114.8 \%$ compared with untreated controls (mean, $73.8 \%$; median, 73.8\%; Gaussian distribution; Fig. 4B). Thus, the inhibitory effect of lysozyme was observed when this was added in concentrations consistent with its physiological range. The non-physiological concentration of $1,000 \mu \mathrm{g} / \mathrm{ml}$ significantly enhanced biofilm production in six strains out of 10 compared with control (Fig. 4B).

The difference in the attached biomass between the two tested lysozyme concentrations (10 and 1,000 $\mu \mathrm{g} / \mathrm{ml})$ was significant for both the reference (Fig. 2B) and the clinical (Fig. 4B) strains (Mann Whitney test, $\mathrm{P}<0.0001$ and $\mathrm{P}=0.0185$, respectively). The increase in the amount of biofilm in the presence of $1,000 \mu \mathrm{g} / \mathrm{ml}$ lysozyme was not significant in clinical strains (Mann Whitney test, $\mathrm{P}=0.1425$ ) but was significant in the reference strain (Mann Whitney test, $\mathrm{P}=0.0013$ ) when compared with control without lysozyme. In contrast, the decrease in attached yeast in the presence of $3 \mu \mathrm{g} / \mathrm{ml}$ lysozyme compared with untreated controls was significant in 8 out of 10 clinical strains (Mann Whitney test, $\mathrm{P}=0.0230$ ). Again, the inhibitory effect of lysozyme was observed in concentrations lower than $30 \mu \mathrm{g} / \mathrm{ml}$, which is considered as the physiological concentration in saliva, while non-physiological concentrations above $100 \mu \mathrm{g} / \mathrm{ml}$ enhanced biofilm production in 6 strains out of 10 .

Lysozyme effect on C. albicans biofilm cohesion. Biofilm cohesion was examined by turbidity variation in wells where C. albicans ATCC 10231 cells were cultured for $24 \mathrm{~h}$ at $37^{\circ} \mathrm{C}$ and subsequently washed three times with sterile $0.9 \% \mathrm{NaCl}$ (Fig. 5). As a control, wells were inoculated with cultures in Sabouraud broth and immediately processed without incubation. In the absence of incubation (and thus without biofilm
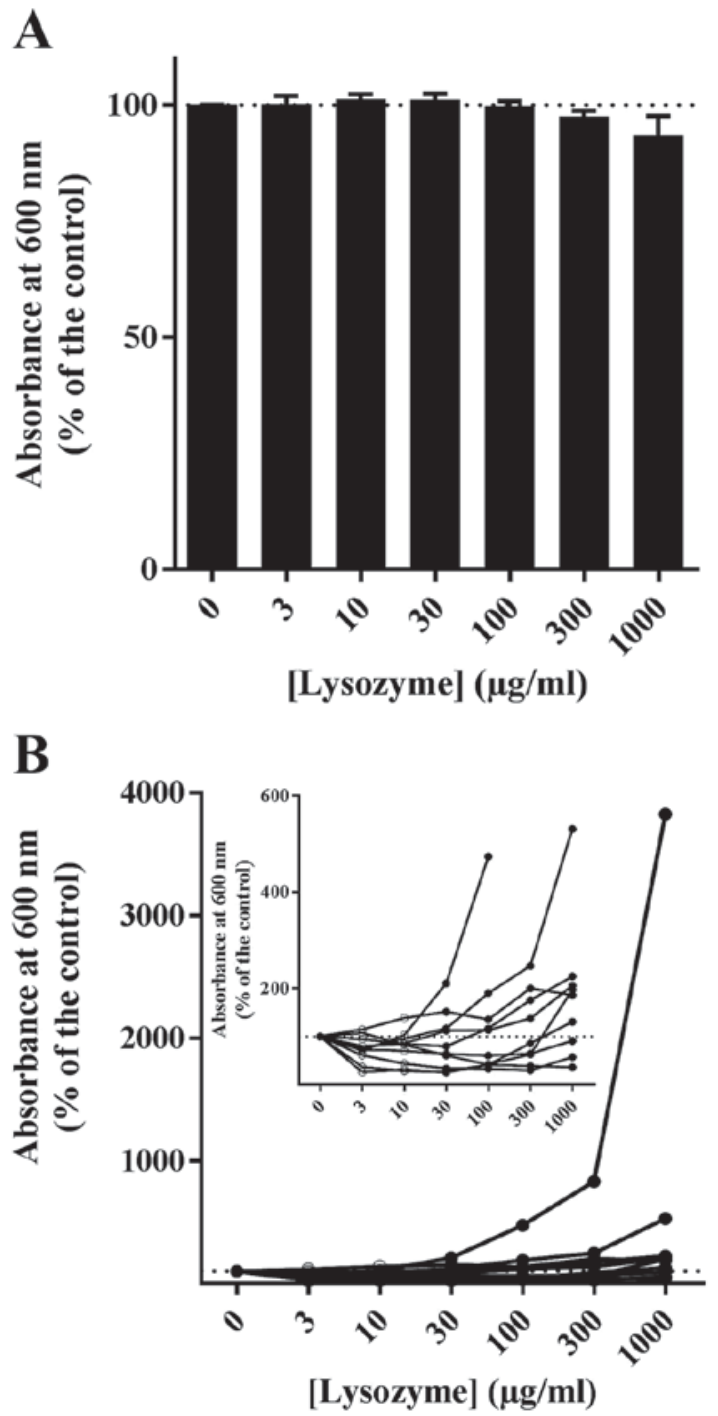

Figure 4. Effect of lysozyme on growth of wild Candida albicans strains. Ten wild $C$. albicans strains were grown for $24 \mathrm{~h}$ at $37^{\circ} \mathrm{C}$ with $0,10,30$, 100,300 or $1,000 \mu \mathrm{g} / \mathrm{ml}$ lysozyme ( $\mathrm{n}=8$ for each condition). (A) Growth was measured by turbidimetry, with results plotted as the mean value for all ten wild strains examined \pm standard error. (B) In vitro biofilm formation was measured by crystal violet staining. Results are plotted separately for each strain examined.

formation), the turbidity underwent a gradual decrease to a residual turbidity of $1.7 \pm 0.7 \%$ relative to the initial supernatant (Fig. 5A). The turbidity of the incubated samples was $627.4 \pm 144.4 \%$ relative to the control after the first washing; turbidity after the second and third washes was $316.3 \pm 59.7$ and $230.4 \pm 23.6 \%$ of that of the culture medium, respectively (Fig. 5A). The effect of lysozyme on cell detachment during the washing process was further examined (Fig. 5B). In the presence of $10 \mu \mathrm{g} / \mathrm{ml}$ lysozyme, the progress of the washing liquid turbidity was similar to the control without lysozyme (Fig. 5B). However, in the presence of $1,000 \mu \mathrm{g} / \mathrm{ml}$ lysozyme, the turbidity following washes was not much greater than the supernatant (Fig. 5B). A two-way ANOVA analysis showed that the washing steps and the lysozyme concentration significantly affected the turbidity of the liquid ( $\mathrm{P}<0.0001$; Fig. 5B). However, the washing steps did not have the same effect at the two concentrations of lysozyme (10 and $1,000 \mu \mathrm{g} / \mathrm{ml}$, 

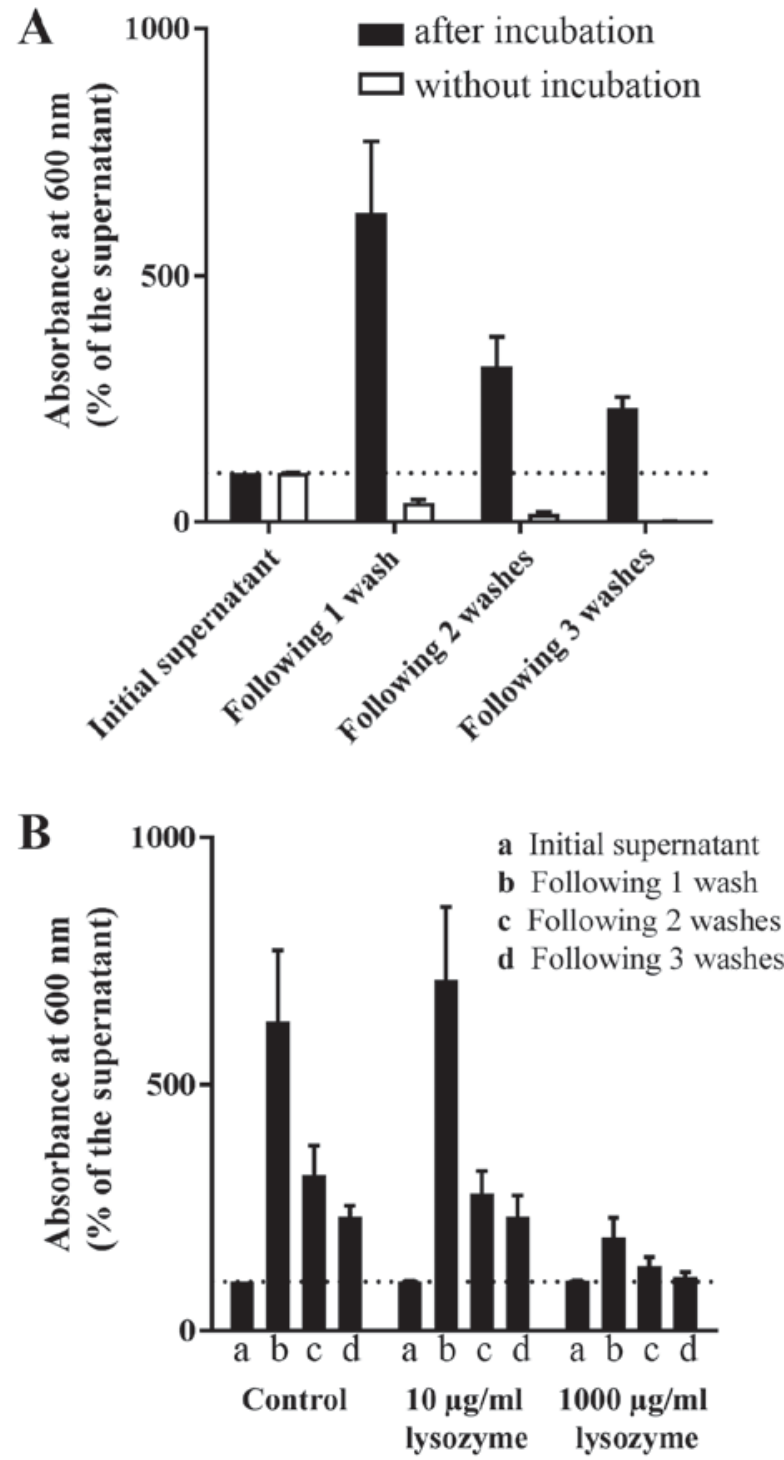

Figure 5. Effect of lysozyme on Candida albicans ATCC 10231 biofilm cohesion. (A) C. albicans ATCC 10231 cells were cultivated for $24 \mathrm{~h}$ at $37^{\circ} \mathrm{C}$ and subsequently washed three times with sterile $0.9 \% \mathrm{NaCl}$. Absorbance at $600 \mathrm{~nm}$ was measured at each step of the washing process. Black columns represent yeast suspensions following $24 \mathrm{~h}$ cultivation at $37^{\circ} \mathrm{C}$; white columns represent the control, where wells were measured from fresh suspension in liquid Sabouraud following no incubation. (B) Absorbance at $600 \mathrm{~nm}$ after each wash was measured in yeast cultured in 0,10 or $1,000 \mu \mathrm{g} / \mathrm{ml}$ of lysozyme $(\mathrm{n}=4$ independent experiments). Data are expressed as the mean \pm standard error of the percentage relative to the absorbance of the initial supernatant ( $\mathrm{n}=4$ independent experiments, 8 technical replicates per condition).

respectively) as shown by the two-way ANOVA analysis for interaction between factors $(\mathrm{P}=0.0101$; Fig. 5B).

C. albicans adhesion on resin. The effect of 10 and $1,000 \mu \mathrm{g} / \mathrm{ml}$ lysozyme on the ability of $C$. albicans to adhere to resin pieces (before and after surface polishing) was examined following $4 \mathrm{~h}$ of incubation at $37^{\circ} \mathrm{C}$ (Fig. 6). A Kolmogorov Smirnov test revealed that the data did not conform to a Gaussian distribution. Lysozyme at $1,000 \mu \mathrm{g} / \mathrm{ml}$ resulted in a mean increase of 10- $(\mathrm{P}=0.0469)$ and 15.7-fold $(\mathrm{P}=0.0781)$ relative to untreated controls for the rough side (median $312.3 \%$ of the control) and the smooth side (median $184.0 \%$ of the control) of the resin foil, respectively (Fig. 6). Lysozyme at $10 \mu \mathrm{g} / \mathrm{ml}$ did not lead

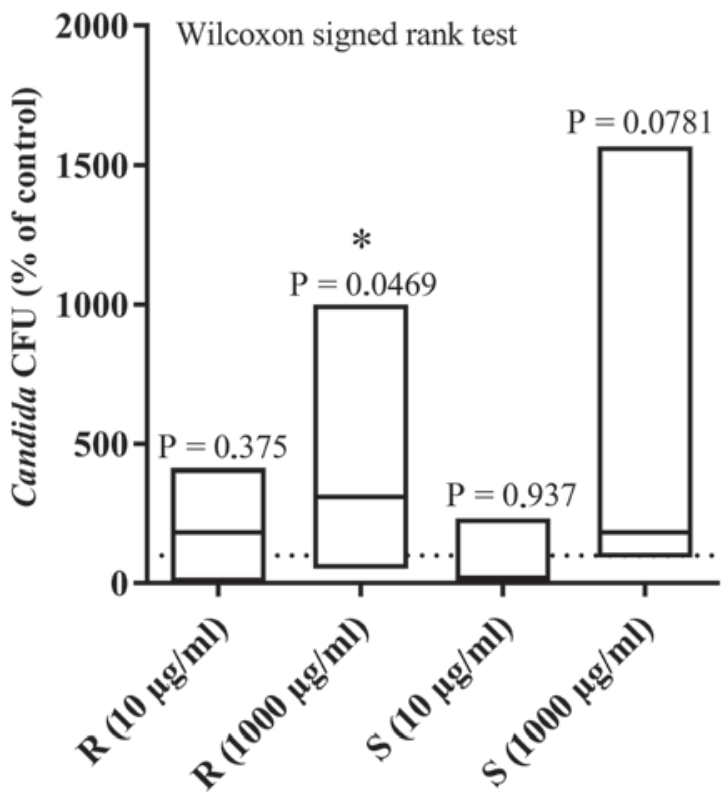

Figure 6. Candida albicans ATCC 10231 adhesion on resin. Yeast adhesion was measured by CFU counts following immersion of acrylic resin foils, with both a rough and smooth surface, in contaminated Sabouraud broth containing lysozyme $(10$ or $1,000 \mu \mathrm{g} / \mathrm{ml})$ for $4 \mathrm{~h}$ at $37^{\circ} \mathrm{C}$. Columns correspond to data range with median ( $\mathrm{n}=7$ independent experiments). ${ }^{*} \mathrm{P}<0.05$ vs. control without lysozyme. CFU, colony forming units; R, rough surface; S, smooth surface.

to significant changes in the attached yeast cell count: 4.1-fold for the rough side (median 184.0\% of the control) and 2.3-fold for the smooth side (median $19.8 \%$ of the control). Analysis of the results by the Wilcoxon signed rank test demonstrated that the high lysozyme concentration $(1,000 \mu \mathrm{g} / \mathrm{ml})$ resulted in significant changes in adherence to the rough resin $(\mathrm{P}=0.0469)$, while the effect on the smooth resin was close to significant $(\mathrm{P}=0.0781)$. Finally, in the absence of lysozyme, polishing negatively affected $C$. albicans adherence to the acrylic surface, as the CFU count on the smooth resin corresponded to $40.8 \pm 7.9 \%$ of that observed on the paired rough resin $(\mathrm{P}=0.0247)$.

\section{Discussion}

Previous investigations have demonstrated that the effect of lysozyme can differ from one bacterial species to another and even within the same bacterial species (37); susceptibility to lysozyme is also dependent on the monitored parameter (growth, viability, cell lysis). In the present study, investigations of $C$. albicans wild strains isolated from dentures revealed several, non-consistent patterns of susceptibility to lysozyme. To the best of our knowledge, no previous studies have focused on biofilm formation and its inhibition by lysozyme from exocrine secretions. In the present study, egg white lysozyme produced a biphasic effect on biofilm formation, while it slightly affected yeast growth tested by turbidimetry. In the $C$. albicans ATCC 10231 reference strain, lysozyme acted as a biofilm promotor at the highest concentration tested $(1,000 \mu \mathrm{g} / \mathrm{ml})$, but as a biofilm limiting factor at the lowest concentration $(10 \mu \mathrm{g} / \mathrm{ml})$. In the clinical strains isolated from contaminated dentures, a variety of responses 
to lysozyme were observed, with no apparent uniform pattern The inhibitory effect of lysozyme was observed at concentrations $<30 \mu \mathrm{g} / \mathrm{ml}$, which are physiological concentrations in saliva (17), while non-physiological doses $>100 \mu \mathrm{g} / \mathrm{ml}$ enhanced biofilm growth. The different results on polystyrene vs. resin are not necessarily attributable to the material itself, since a different method of attached biomass evaluation was used for each material (crystal violet staining vs. CFU counts following seeding, respectively). However, because of crystal violet adsorption on resin pieces in the absence of $C$. albicans cells (data not shown), a different method had to be employed. Although less sensitive than a colorimetric assay, CFU counts on Petri dishes presented the advantage of confirming the viability of attached biomass without additional manipulation.

Pro-biofilm effect of lysozyme on C. albicans. In the present study, a pro-biofilm property for lysozyme was suggested in different strains, on two different support materials (polystyrene, widely used in the laboratory, and acrylic resin, widely used in the fabrication of dentures), by two different experimental designs (C. albicans adhesion to the material surface and biofilm production), and by two different biofilm production assessments (crystal violet staining and CFU counts). Lysozyme capacity to increase attached biomass was observed at high but non-physiological concentrations. The FDA/EB staining assay revealed that the majority of cells attached in the presence of $1 \mathrm{mg} / \mathrm{ml}$ lysozyme were alive. The pro-biofilm property of lysozyme on C. albicans ATCC 10231 is more pronounced when added simultaneously with the $C$. albicans cells, suggesting a crucial role in the adherence phase of the biofilm formation. The pro-biofilm effect was also confirmed by the assessment of biofilm cohesion during three successive washes with saline. In the presence of $1,000 \mu \mathrm{g} / \mathrm{ml}$ lysozyme, the turbidity of the washing media did not increase, which suggests low yeast cell loss by the biofilm. Previous studies have focused on the agglutination or flocculation power of lysozyme (at a cited concentration of $1 \mathrm{mg} / \mathrm{ml}$ ) in non-ionic solutions upon air saprophytes (22), bacterial suspensions (38) or $C$. albicans yeasts (22). The presence of lysozyme in the in vivo acquired exogenous pellicle on teeth is well documented but no data concerning its effect on biofilm formation exist to date (39). The present study demonstrated an increase in $C$. albicans adherence in six out of ten wild $C$. albicans strains when higher concentrations of lysozyme were present, suggesting that the use of high concentrations on lysozyme in oral care products may be unfitting. Intra-species variability in lysozyme susceptibility has also previously been demonstrated in bacteria (37).

Anti-biofilm effect of lysozyme on C. albicans. In the present study, low concentrations of lysozyme $(<30 \mu \mathrm{g} / \mathrm{ml})$ resulted in a reduction in the attached biomass. At a concentration of $10 \mu \mathrm{g} / \mathrm{ml}$, biofilm reduction on polystyrene was observed in C. albicans ATCC 10231 and in 3 out of 10 clinical strains investigated. The anti-biofilm effect was not observed for the reference strain on either a rough $(\mathrm{P}=0.375)$ or smooth $(\mathrm{P}=0.937)$ resin support. However, a previous study has demonstrated that a similar concentration range of lysozyme $(6-100 \mu \mathrm{g} / \mathrm{ml})$ significantly inhibited $C$. albicans biofilm formation on an acrylic resin surface (33). In contrast, a separate study demonstrated no significant reduction in C. albicans attachment on acrylic resin disks immersed in a solution containing lysozyme, lactoferrin and glucose oxidase complex/lactoperoxidase (35). These conflicting observations are consistent with the present study, where the susceptibility of $C$. albicans wild strains to lysozyme differed from one another.

Inhibitory effect of lysozyme upon C. albicans growth. The present study demonstrated a significant effect of egg white lysozyme on yeast growth at lysozyme concentrations $>300 \mu \mathrm{g} / \mathrm{ml}$ for the reference strain, but not for the wild strains. The growth reduction effect on $C$. albicans ATCC 10231 in Sabouraud liquid medium upon exposure to 1,000 and $300 \mu \mathrm{g} / \mathrm{ml}$ lysozyme was $9.0 \pm 1.6$ and $5.3 \pm 0.9 \%$, respectively, compared with control. In the clinical isolates, a similar mild reduction was observed but was not statistically significant. It is possible that this small effect may be due to the incorporation of planktonic cells into the attached biomass on the lateral sides of the microplate wells, thus escaping the photometric evaluation. The effect on the turbidimetric measurement can then be explained by the pro-biofilm property of the lysozyme. Previously, $C$. albicans cells have been observed to be lysed by lysozyme (in a concentration range from 40 to $5,000 \mu \mathrm{g} / \mathrm{ml}$ ) independently of the amount of glucose present, but this effect was prevented by the addition of $\mathrm{NaCl}$ to the culture medium (40).

The present study demonstrated differing effects of lysozyme upon in vitro $C$. albicans biofilm formation dependent on its concentration: anti-biofilm at physiological concentrations and pro-biofilm with concentrations $>300 \mu \mathrm{g} / \mathrm{ml}$. The present study thus indicates that the concentration of active compounds should be stated in oral care products. In addition, the present study illustrates the challenges of comprehensively understanding the complex relationships between oral microflora and salivary antimicrobial systems. As well as careful and detailed reporting, new tools should be developed to study the relationship between the microbiome and its exocrine environment, taking into account the diversity of antimicrobial factors and the concentration of each. The present study emphasizes the necessity of developing strategies for biofilm control based on in vitro experiments, and to implement them in clinical trials prior to the incorporation of exocrine proteins, such as lysozyme, into hygiene products. Further studies should extend these investigations to other Candida species, and to fungi and bacteria present in oral biofilms, using a more global approach.

\section{Acknowledgements}

The present study was supported by a grant (grant no. BRIC-12/143) from the Xenophilia Funds (Université Libre de Bruxelles, Brussels, Belgium). The authors thank P. Keyzer for manufacturing the acrylic pieces and Professor M. Stas for her review of the manuscript.

\section{References}

1. Radford DR, Challacombe SJ and Walter JD: Denture plaque and adherence of Candida albicans to denture-base materials in vivo and in vitro. Crit Rev Oral Biol Med 10: 99-116, 1999. 
2. Courtois Ph: Candida biofilms on oral biomaterials. In: Biomaterials-Physics and chemistry. Pignatello R (ed.) Intech, Rjieka, pp475-490, 2011.

3. Epstein JB, Truelove EL and Izutzu KT: Oral candidiasis: Pathogenesis and host defense. Rev Infect Dis 6: 96-106, 1984.

4. Webb BC, Thomas CJ, Willcox MD, Harty DW and Knox KW: Candida-associated denture stomatitis. Aetiology and management: A review. Part 1. Factors influencing distribution of Candida species in the oral cavity. Aust Dent J 43: 45-50, 1998.

5. Ramage G, Tomsett K, Wickes BL, López-Ribot JL and Redding SW: Denture stomatitis: A role for Candida biofilms. Oral Surg Oral Med Oral Pathol Oral Radiol Endod 98: 53-59, 2004.

6. Fleming A: On a remarkable bacteriolytic element found in tissues and secretions. Proc R Soc Lond B Biol Sci 93: 306-317, 1922.

7. Gordon S, Todd $\mathrm{J}$ and Cohn ZA: In vitro synthesis and secretion of lysozyme by mononuclear phagocytes. J Exp Med 139: $1228-1248,1974$

8. Vukosavljevic D, Custodio W and Siqueira WL: Salivary proteins as predictors and controls for oral health. J Cell Commun Signal 5: 271-275, 2011.

9. Fábián TK, Hermann P, Beck A, Fejérdy P and Fábián G: Salivary defense proteins: Their network and role in innate and acquired oral immunity. Int J Mol Sci 13: 4295-4320, 2012.

10. Phillips DC: The three-dimensional structure of an enzyme molecule. Sci Am 215: 78-90, 1966.

11. Masschalck B and Michiels CW: Antimicrobial properties of lysozyme in relation to foodborne vegetative bacteria. Crit Rev Microbiol 29: 191-214, 2003

12. MacKay BJ, Goodman H, Cox D, Grossbard BL, Iacono VJ and Pollock JJ: Development of an enzyme-linked immunosorbent assay for determination of lysozyme in human parotid and submandibular-sublingual salivas. J Clin Microbiol 19: 844-848, 1984.

13. Noble RE: Salivary alpha-amylase and lysozyme levels: A non-invasive technique for measuring parotid vs submandibular/sublingual gland activity. J Oral Sci 42: 83-86, 2000.

14. Brandtzaeg P and Mann WV Jr: A comparative study of the lysozyme activity of human gingival pocket fluid, serum and saliva. Acta Odontol Scand 22: 441-455, 1964

15. Eisenberg RJ, Bowers GM and Bergquist JJ: Lysozyme activity in gingival crevicular fluid. J Baltimore Coll Dent Surg 32: 83-85, 1977.

16. Sakalauskiene J, Surna A, Ivanauskiene E, Zekonis G and Gleiznys A: Secretory function of neutrophilic leucocytes of the patients with periodontal diseases. Stomatologija 7: 90-94, 2005

17. Stuchell RN and Mandel ID: A comparative study of salivary lysozyme in caries-resistant and caries-susceptible adults. J Dent Res 62: 552-554, 1983.

18. Woods CM, Hooper DN, Ooi EH, Tan LW and Carney AS: Human lysozyme has fungicidal activity against nasal fungi. Am J Rhinol Allergy 25: 236-240, 2011.

19. Marquis G, Montplaisir S, Garzon S, Strykowski H and Auger P: Fungitoxicity of muramidase. Ultrastructural damage to Candida albicans. Lab Invest 46: 627-636, 1982.

20. Marquis G, Garzon S, Strykowsky H and Auger P: Cell walls of normal and lysozyme-damaged blastoconidia of Candida albicans: Localization of surface factor 4 antigen and vicinal-glycol staining. Infect Immun 59: 1312-1318, 1991.

21. Edgerton M and Koshlukova SE: Salivary histatin 5 and its similarities to the other antimicrobial proteins in human saliva. Adv Dent Res 14: 16-21, 2000
22. Kamaya T: Flocculation phenomenon of Candida albicans by lysozyme. Mycopathol Mycol Appl 37: 320-330, 1969.

23. Tenovuo J: Clinical applications of antimicrobial host proteins lactoperoxidase, lysozyme and lactoferrin in xerostomia: Efficacy and safety. Oral Dis 8: 23-29, 2002.

24. Gil-Montoya JA, Guardia-López I and González-Moles MA Evaluation of the clinical efficacy of a mouthwash and oral ge containing the antimicrobial proteins lactoperoxidase, lysozyme and lactoferrin in elderly patients with dry mouth: A pilot study. Gerodontology 25: 3-9, 2008.

25. Güneri P, Alpöz E, Epstein JB, Cankaya $\mathrm{H}$ and Ates M: In vitro antimicrobial effects of commercially available mouth-wetting agents. Spec Care Dentist 31: 123-128, 2011.

26. Lee JY, Kim YY, Chang JY, Park MS and Kho HS: The effects of peroxidase on the enzymatic and candidacidal activities of lysozyme. Arch Oral Biol 55: 607-612, 2010.

27. Cho MA, Kim YY, Chang JY and Kho HS: Interactions between hyaluronic acid, lysozyme, and the glucose oxidase-mediated lactoperoxidase system in enzymatic and candidacidal activities. Arch Oral Biol 58: 1349-1356, 2013.

28. Samaranayake YH, Samaranayake LP, Wu PC and So M: The antifungal effect of lactoferrine and lysozyme on Candida kruse and Candida albicans. APMIS 105: 875-883, 1997.

29. Kang JH, Kim YY, Chang JY and Kho HS: Influences of hyaluronic acid on the anticandidal activities of lysozyme and the peroxidase system. Oral Dis 17: 577-583, 2011.

30. Collins MS and Pappagianis D: Lysozyme-enhanced killing of Candida albicans and Coccidioides immitis by amphoteracin B. Sabouraudia 12: 329-340, 1974

31. Nishiyama $Y$, Nakaoka $C$, Hiratani $T$, Abe $S$, Uchida $K$ and Yamaguchi H: Synergy of lysozyme and lanoconazole on the morphology of Candida albicans. JElectron Microsc (Tokyo) 50: 41-49, 2001.

32. Anil S and Samaranayake LP: Impact of lysozyme and lactoferrin on oral Candida isolates exposed to polyene antimycotics and fluconazole. Oral Dis 8: 199-206, 2002.

33. Samaranayake YH, Cheung BP, Parahitiyawa N, Seneviratne CJ, Yau JY, Yeung KW and Samaranayake LP: Synergistic activity of lysozyme and antifungal agents against Candida albicans biofilms on denture acrylic surfaces. Arch Oral Biol 54: 115-126, 2009.

34. Tanida T, Okamoto T, Okamoto A, Wang H, Hamada T, Ueta E and Ozaki T: Decreased excretion of antimicrobial proteins and peptides in saliva of patients with oral candidiasis. J Oral Pathol Med 32: 586-594, 2003.

35. Silva MP, Chibebe Junior J, Jorjão AL, Machado AK, Oliveira LD, Junqueira JC and Jorge AO: Influence of artificial saliva in biofilm formation of Candida albicans in vitro. Braz Oral Res 26: 24-28, 2012.

36. Stepanovic S, Vukovic D, Dakic I, Savic B and Svabic-Vlahovic M A modified microtiter-plate test for quantification of staphylococcal biofilm formation. J Microbiol Methods 40: 175-179, 2000.

37. Iacono VJ, MacKay BJ, DiRienzo S and Pollock JJ: Selective antibacterial properties of lysozyme for oral microorganisms. Infect Immun 29: 623-632, 1980.

38. Salton MR: Cell structure and the the enzymic lysis of bacteria. J Gen Microbiol 9: 512-523, 1953.

39. Edgerton $M$ and Levine MJ: Characterization of acquired denture pellicle from healthy and stomatitis patients. J Prosthet Dent 68: 683-691, 1992

40. Kamaya T: Lytic action of lysozyme on Candida albicans. Mycopathol Mycol Appl 42: 197-207, 1970. 